DOI: http://dx.doi.org/10.18764/2358-4319.v12n3p157-180

\title{
Trabalhadores docentes sob novas acusações
}

\author{
Frederico Guilherme Campos de França' \\ Solange Cardoso ${ }^{2}$
}

\section{RESUMO}

Este artigo tem como objetivo realizar uma discussão teórica acerca do trabalho docente, considerando-o central nas relações entre o capital e as condições materiais que envolvem a vida profissional dos professores. A presente discussão perpassa a ascensão do pensamento neoliberal, ocorrida no final dos anos de 1970, na Inglaterra de Margareth Thatcher e nos Estados Unidos de Ronald Reagan. O contexto de análise inclui o cenário deflagrado pelo resultado da eleição para presidente do Brasil, no ano de 2018, em que o programa de governo do candidato eleito é alinhado às orientações e perspectivas do Banco Mundial, poderoso representante do capitalismo globalizado. Mediante os dados de remuneração do trabalho docente, no Brasil, com destaque para o Distrito Federal, procurou-se comparar a situação do trabalho docente em relação aos argumentos do referido Banco e do novo Governo. As análises apresentadas, ao longo do artigo, indicam que os professores brasileiros estão sendo tratados/apontados como um dos problemas graves para o alcance de uma educação de qualidade e que o trabalho docente vem sendo colocado como ineficiente, pouco comprometido, muito caro e amplamente ligado a causas político-partidárias. Contudo, mesmo diante de um quadro desfavorável, no qual se começa a criar a imagem dos professores como inimigos da nação, muitos docentes continuam na resistência e na luta por melhores condições de trabalho e prestígio social.

Palavras-chave: Trabalho Docente. Professores. Educação.

1 Mestrando em Educação pelo Programa de Pós-Graduação em Educação da Faculdade de Educação da Universidade de Brasília. ORCID: http://orcid.org/0000-0001-8827-4732. Email: fredecampos@gmail.com

2 Mestre em Educação pela Universidade Federal de Ouro Preto. Doutoranda em Educação pelo Programa de Pós-Graduação em Educação da Faculdade de Educação da Universidade de Brasília. Membro do Grupo de Estudos e Pesquisas sobre Formação e Atuação de Professores/Pedagogos (GEPFAPe. ORCID: http://orcid.org/0000-0003-3433-9937. Email: solangecardoso1908@gmail.com 


\title{
Teaching workers under new indictments
}

\begin{abstract}
This article aims to conduct a theoretical discussion about teaching work, considering it central in the relations between capital and the material conditions that involve the professional life of teachers. This discussion runs through the rise of neoliberal thinking in the late 1970 s in Margareth Thatcher's England and Ronald Reagan's United States. The context of analysis includes the scenario triggered by the result of the election of the President of Brazil in 2018, whose program of government of the elected candidate is aligned with the orientations and perspectives of the World Bank, a powerful representative of globalized capitalism. Through data on the remuneration of teaching work in Brazil, especially the Federal District, we sought to compare the situation of teaching work in relation to the arguments of the Bank and the new Government. The analyzes presented throughout the article indicate that Brazilian teachers are being treated / pointed as one of the serious problems for the achievement of quality in education and that the teaching work has been placed as inefficient, little compromised, very expensive and widely. linked to partisan political causes. However, even in the face of an unfavorable scenario in which teachers are being created as enemies of the nation, many teachers continue to resist and fight for better working conditions and social prestige.
\end{abstract}

Keywords: Teaching Work. Teachers. Education.

\section{Trabajadores docentes bajo nuevas acusiones}

\section{RESUMEN}

Este artículo tiene como objetivo llevar a cabo una discusión teórica sobre el trabajo docente, considerándolo central en las relaciones entre el capital y las condiciones materiales que involucran la vida profesional de los docentes. Esta discusión se acerca a la ascensión del pensamiento neoliberal a finales de los años de 1970 en la Inglaterra de Margareth Thatcher y en Estados Unidos de Ronald Reagan. El contexto de análisis incluye el escenario influido por el resultado de la elección del Presidente de Brasil en 2018, cuyo programa de gobierno del candidato elegido está volcado a las orientaciones y perspectivas del Banco Mundial, un poderoso representante del capitalismo globalizado. Mediante los datos 
de remuneración del trabajo docente, en Brasil, con destaque para el Distrito Federal, se buscó comparar la situación del trabajo docente en relación con los argumentos del Banco y del nuevo Gobierno. Los análisis presentados a lo largo del artículo indican que los docentes brasileños están siendo tratados / señalados como uno de los problemas serios para el alcance de una educación de calidad y que el trabajo docente se ha puesto como ineficiente, poco comprometido, muy costoso y ampliamente. vinculado con las causas políticas partidarias. Sin embargo, ante un escenario desfavorable en el que comienza a crear la imagen de los docentes como enemigos de la nación, muchos docentes continúan en la resistencia y en la lucha por mejores condiciones de trabajo y prestigio social.

Palabras clave: Trabajo Docente. Maestros. Educación.

\section{Introdução}

\section{“Nada existe; mesmo que existisse, seria incognoscível; mesmo que fosse cognoscível, seria incomunicável!" (Górgias de Leontini)}

Desde que foi apresentada uma nova política em relação à organização do trabalho com a propagação mundial do pensamento neoliberal - concretizado no final dos anos de 1970, na Inglaterra de Margareth Thatcher e nos Estados Unidos de Ronald Reagan (HARVEY, 2008) -, as políticas públicas voltadas para a educação no Estado brasileiro têm apresentado novas perspectivas. A ascensão do neoliberalismo ao posto de filosofia preponderante do sistema do capital, nesse mesmo período, intensificou o processo de globalização com a promoção da abertura de mercados, para além das distâncias, entre os países ou mesmo entre suas fronteiras.

Contudo, como nos admoestou Milton Santos (2017), a propalada globalização possui alguns vieses que precisam ser conhecidos. Em sua análise:"O primeiro seria o mundo tal como nos fazem vê-lo: a globalização como fábula; o segundo seria o mundo tal como ele é: a globalização como perversidade; e o terceiro, o mundo como ele pode ser: uma outra globalização" (SANTOS, 2017, p. 18). O referido autor aponta que a globalização que os meios de comunicação divulgam para as massas, a serviço do grande capital, é revestida de uma roupagem que nos leva a acreditar que pode ser a salvadora da humanidade. Assim, enquanto a 
globalização real aprofunda enormemente as diferenças entre as nações e as pessoas, criando uma legião de excluídos e marginalizados, esses meios criam um ofuscamento para que, de fato, não seja compreendida, debatida e questionada. Gramsci, no início do século XX, já discorria sobre essa globalização capitalista:

A imprensa é a parte mais dinâmica desta estrutura ideológica, mas não a única: tudo o que influi ou pode influir sobre a opinião pública, direta ou indiretamente, faz parte dessa estrutura. Dela fazem parte: as bibliotecas, as escolas, os círculos e os clubes de variado tipo, até a arquitetura, a disposição e o nome das ruas. Não se explicaria a posição conservada pela Igreja na sociedade moderna se não se conhecessem os esforços diuturnos e pacientes que ela faz para desenvolver continuamente sua seção particular desta estrutura material da ideologia (GRAMSCI, 2006, p. 78).

No Brasil, esse conjunto de meios de comunicação - também denominado de imprensa, por Gramsci -, influi não apenas nos costumes e linguajares de uma geração, mas também na definição do comando político do país. Da mesma forma, o comando político adota os preceitos de um capitalismo que exige a retirada do Estado, o máximo possível, da organização da sociedade, deixando o mercado livre para exercer o controle e exigir a reestruturação do modelo produtivo e das relações trabalhistas. Assim, tais

[...] reestruturações traduziram-se em mudanças dramáticas, tanto no uso da força de trabalho quanto nos processos e nos mercados de trabalho. Cabe salientar que os efeitos se traduziram, conforme Castells $^{3}$ (1999), em um declínio no emprego industrial, queda dos salários reais, aumento da desigualdade e instabilidade no emprego, precarização do trabalho e desvalorização da mão de obra (HYPOLITO; GRISHCKE, 2013, p. 508).

Nesse cenário, embora os autores tenham focado o emprego industrial, essa reestruturação não se limitou ao setor secundário da economia, uma vez que a educação foi subsumida ao mesmo conjunto de ações. A educação pública no Brasil, por exemplo, ao ser engajada como setor de vital importância para o crescimento do capitalismo, manuten-

3 CASTELLS, M. A sociedade em rede. São Paulo: Paz e Terra, 1999. 
ção e ampliação do poder, ao mesmo tempo, carrega em si a contradição de possibilitar - a um grande número de pessoas - a compreensão do caminho para a emancipação coletiva, pois:

A educação se opera, na sua totalidade dialética, como um processo que conjuga as aspirações e necessidades do homem no contexto objetivo de sua situação histórico-social. A educação torna-se, então, uma atividade humana partícipe da totalidade da organização social. (CURY, 1989, p. 13).

Conforme o autor, a educação é feita por pessoas, com todas as suas idiossincrasias e necessidades impostas pelas condições materiais de existência.

Por conseguinte, observa-se, ainda, o posicionamento de resguardar o modelo de Capitalismo recente, cuja proposta é ser mais justo para as massas populacionais, em detrimento do modelo de Socialismo soviético (adotado em Cuba, China, Coreia do Norte, Vietnã etc.) - experimentado no Leste Europeu, desde o início do século passado -, bem como o welfare state, o estado-providência ou estado de bem-estar social (ROSANVALLON, 1997), que caíram em franco desuso à medida que a 'guerra fria' perdeu força.

Em contradição, desfigura-se cada vez mais a imagem do ser humano no mundo tecnológico, pois sua práxis na criação e transformação da natureza passa a ser gradualmente diminuída e o trabalho, nessa condição, torna-se trivial e sem maior importância. Nessa perspectiva, o capitalismo alimenta a ideia do trabalhador como um problema para os avanços da economia, difundindo, assim, o trabalho como algo que melhor seria feito por autômatos. Nada próximo da centralidade do trabalho na ontologia do ser social, o qual indica que: "[...] o trabalho é antes de mais nada, em termos genéticos, o ponto de partida da humanização do homem, do refinamento das suas faculdades, processo do qual não se deve esquecer o domínio sobre si mesmo" (LUKÁCS, 1979, p. 87).

\section{Trabalhar sem reconhecimento}

As recentes transformações que o Brasil vem sofrendo em seu sistema político e na forma de se administrar o país, especialmente desde o golpe parlamentar de 2016 que retirou uma Presidenta ree- 
leita em 2014 - sobre a qual, agora, se admite a não comprovação de crime algum -, culminaram com a ascensão ao comando do país, em 2018, de um grupo político extremamente reacionário. O novo Governo Federal tem demonstrado uma temerária fusão de fanatismo religioso com políticas neoliberais de Estado Mínimo, com total abertura da economia e com a venda do patrimônio nacional, aliando-se, ainda, a militares remanescentes ou saudosistas do período da ditadura militar. Desde o primeiro momento, essa perigosa fusão política - que em menos de seis meses de governo tem criado polêmicas e instabilidades, especialmente a respeito da população pobre, preta, indígena e LGBT -, se posicionou contra políticas públicas inclusivas, principalmente na área da Educação, além de pôr em dúvida a qualidade do trabalho docente no país. Nesse contexto, o trabalho dos professores vem sendo colocado como ineficiente, pouco comprometido, muito caro e amplamente ligado a causas político-partidárias. Enquanto essa discussão acontece, a carreira docente agoniza, retrocede e vem sendo atirada ao grupo estereotipado como os "privilegiados" da sociedade brasileira.

Para os professores, formação de qualidade é condição sine qua non no desenvolvimento da docência e de sua própria organização como membros da classe trabalhadora. Nessa perspectiva, uma formação que não Ihe ajuda a reconhecer as contradições - o movimento dialético que envolve sua atividade, as lutas envolvidas e os meios para o enfrentamento -, pode acabar em sua absolvição e cooptação para a defesa de um modelo de educação que não lhe contempla. Por isso:

Se o professor não realiza um constante processo de estudo das teorias pedagógicas e das várias ciências, se ele não se apropriar desses conhecimentos, ele terá grande dificuldade de fazer de seu trabalho docente uma atividade que se diferencie do espontaneísmo que caracteriza o cotidiano alienado da sociedade capitalista contemporânea [...] (FACCl, 2004, p. 244).

Para Facci (2004), a sociedade capitalista contemporânea vê a educação como ambiente propício para a geração de lucros. A transposição do pensamento economicista de que a prestação de serviços públicos precisa ser avaliada segundo a ótica da produtividade aplicada na produção industrial, sob regulações empresariais, transforma o 
Estado em um ente sob gestão puramente gerencial (BRESSER-PEREIRA, 1998). Nesse sentido, a educação pública sente por completo os impactos dessa forma de pensamento ao ser tratada como um setor que deva seguir o modelo gerencial/empresarial que vise ao lucro a qualquer custo.

Com a educação, cada vez mais, encarada como comércio, os professores passam a novos tipos de relações no trabalho que desenvolvem. Por isso, uma crescente ideologia de culpabilização dos professores vem sendo posta em prática. Por exemplo, as análises e sugestões feitas pelo Banco Mundial - a pedido do governo brasileiro, em 2017 -, no documento denominado "Um ajuste justo". O estudo realizado pelo banco concluiu que apesar de todos os problemas e ineficiências dos professores brasileiros, eles são bem pagos e gozam de privilégios perante professores de outras nações do planeta. Diz o documento:

\begin{abstract}
A baixa qualidade dos professores é o principal fator restringindo a qualidade da educação. O magistério permanece uma profissão desprestigiada. Os requisitos para ingresso em cursos de licenciatura são fracos e a formação é de baixa qualidade. [...] Os salários iniciais dos professores do ensino básico encontram-se em linha com níveis internacionais (como percentual do PIB per capita), mas superam rapidamente os níveis internacionais devido a promoções automáticas [...] No entanto, os salários dos professores no Brasil aumentam rapidamente após o início da carreira. Devido às promoções automáticas baseadas nos anos de serviço e da participação em programas de formação, em 15 anos de carreira os salários se tornam duas a três vezes superiores ao salário inicial, em termos reais. Essa evolução supera significativamente a maioria dos países no mundo [...] (BANCO MUNDIAL, 2017, p. 127).
\end{abstract}

O Banco Mundial restringe sua análise sobre a situação da educação brasileira à condição do professor. Para essa instituição, a baixa qualidade dos professores aliada a uma remuneração alta diante de resultados precários aponta escandalosa ineficiência. Mas, enquanto isso, não apenas as condições de trabalho e as características de país subdesenvolvido - concentrador de riquezas, oligarca e periférico na Divisão Internacional do Trabalho - são esquecidas, mas também as diferenças regionais tão discrepantes do Brasil parecem nem existirem. 
Em 2018, na eleição para Presidência da República do Brasil, treze candidatos concorreram, submetendo seus planos de governo ao Tribunal Superior Eleitoral (TSE), para consulta pública. O candidato vencedor do pleito, no segundo turno, foi Jair Messias Bolsonaro, do Partido Social Liberal (PSL), cujo plano de governo foi registrado sob o título: "Brasil acima de tudo. Deus acima de todos". Em seu plano, as propostas do então candidato se alinham ao Banco Mundial, por exemplo, na seguinte afirmação:

\begin{abstract}
Na educação, assim como na saúde, os números levam à conclusão que as crianças e os jovens brasileiros deveriam ter um desempenho escolar muito meIhor, tendo em vista o montante de recursos gastos. Os valores, tanto em termos relativos como em termos absolutos, são incompatíveis com nosso péssimo desempenho educacional. [...] Conteúdo e método de ensino precisam ser mudados (BRASIL, 2018, p. 41).
\end{abstract}

Nessa lógica, tanto o Banco Mundial como o candidato eleito Presidente, em 2018, consideram os professores brasileiros bem pagos e a educação com verba mais que suficiente, porém, indicam a prestação de serviços com péssimos resultados. Entretanto, tais ilações são pouco fundamentadas e, em alguns pontos, inverídicas. Afinal, como o mesmo trecho da exposição do banco consegue admitir: "o magistério permanece uma profissão desprestigiada" (BANCO MUNDIAL, 2017, p. 127).

A respeito da remuneração dos professores brasileiros, tão elevada segundo o Banco e seus simpatizantes, alguns dados mostram uma realidade bastante diferente. Segundo o site Trading Economics (2018), a hora de trabalho nos Estados Unidos, no ano de 2018 , ficou em média em US\$22,95. Se esse valor for considerado como referência, o professorado brasileiro que trabalha 40 horas por semana teria uma remuneração de \$3.672 Dólares ao final de um mês de trabalho, correspondendo, em reais, ao total de $14.210,64$. Se os professores da educação básica pública brasileiros são tão privilegiados, conforme alegam, como compreender os atuais salários dos professores nos Estados e Distrito Federal? Tomando por base o salário mínimo atual do país, de 954,00 (DIEESE, 2018) e o dólar americano, por exemplo, cotado em 3,87 (INFOMONEY, 2018), teríamos a seguinte situação: 
Tabela 1 - Comparativos das remunerações dos professores estaduais no Brasil

\begin{tabular}{|c|c|c|c|c|}
\hline Esta & ado & $\begin{array}{c}\text { Vencimentos } \\
\text { em Reais }\end{array}$ & $\begin{array}{c}\text { Em salários } \\
\text { mínimos }\end{array}$ & $\begin{array}{l}\text { Em Dóla- } \\
\text { res (US\$ }\end{array}$ \\
\hline 1 & Mato Grosso ${ }^{4}$ & $5.799,46$ & 6,08 & $1.498,57$ \\
\hline 2 & Mato Grosso do Sul ${ }^{5}$ & $5.757,28$ & 6,03 & $1.487,67$ \\
\hline 3 & Maranhão & $5.750,84$ & 6,03 & $1.486,01$ \\
\hline 4 & Distrito Federal & $5.016,53$ & 5,26 & $1.296,26$ \\
\hline 5 & Tocantins & $4.507,94$ & 4,73 & $1.164,84$ \\
\hline 6 & Amapá & $4.215,95$ & 4,42 & $1.089,39$ \\
\hline 7 & Pará & $4.187,51$ & 4,39 & $1.082,04$ \\
\hline 8 & Sergipe & $4.137,84$ & 4,34 & $1.069,21$ \\
\hline 9 & Roraima & $4.005,82$ & 4,20 & $1.035,10$ \\
\hline 10 & Minas Gerais ${ }^{6}$ & $3.557,78$ & 3,73 & 919,32 \\
\hline 11 & Amazonas & $3.511,76$ & 3,68 & 907,43 \\
\hline 12 & Espírito Santo $^{7}$ & $3.496,16$ & 3,66 & 903,40 \\
\hline 13 & Ceará & $3.394,43$ & 3,56 & 877,11 \\
\hline 14 & Rio Grande do Norte & $3.218,30$ & 3,37 & 831,60 \\
\hline 15 & Alagoas & $3.018,75$ & 3,16 & 780,04 \\
\hline 16 & Piauí & $2.960,00$ & 3,10 & 764,86 \\
\hline 17 & Acre $^{9}$ & $2.855,28$ & 2,99 & 737,80 \\
\hline 18 & Paraná ${ }^{10}$ & $2.831,56$ & 2,97 & 731,67 \\
\hline 19 & Bahia & $2.814,28$ & 2,95 & 727,20 \\
\hline
\end{tabular}

4 Carga na carreira é de 20 horas. $O$ valor apresentado, de 40 horas, foi calculado pelos autores do artigo.

5 Carga na carreira é de 20 horas. O valor apresentado, de 40 horas, foi calculado pelos autores do artigo.

6 Carga na carreira é de 24 horas. $O$ valor apresentado, de 40 horas, foi calculado pelos autores do artigo.

7 Carga na carreira é de 25 horas. 0 valor apresentado, de 40 horas, foi calculado pelos autores do artigo.

8 Carga na carreira é de 30 horas. $O$ valor apresentado, de 40 horas, foi calculado pelos autores do artigo.

9 Carga na carreira é de 30 horas. 0 valor apresentado, de 40 horas, foi calculado pelos autores do artigo.

10 Carga na carreira é de 20 horas. O valor apresentado, de 40 horas, foi calculado pelos autores do artigo. 


\begin{tabular}{l|l|c|c|c}
\hline \multicolumn{2}{l|}{ Estado } & $\begin{array}{c}\text { Vencimentos } \\
\text { em Reais } \\
\mathbf{4 0} \text { horas }\end{array}$ & $\begin{array}{c}\text { Em salários } \\
\text { mínimos } \\
\mathbf{( 9 5 4 , 0 0 )}\end{array}$ & $\begin{array}{c}\text { Em Dóla- } \\
\text { res (US\$ } \\
\mathbf{3 , 8 7})\end{array}$ \\
\hline 20 & Santa Catarina & $2.705,87$ & 2,84 & 699,19 \\
\hline 21 & São Paulo & $2.585,00$ & 2,71 & 667,96 \\
\hline 22 & Rondônia & $2.581,86$ & 2,71 & 667,15 \\
\hline 23 & Paraíba11 & $2.528,68$ & 2,65 & 653,41 \\
\hline 24 & Goiás & $2.470,62$ & 2,59 & 638,40 \\
\hline 25 & Pernambuco & $2.455,35$ & 2,57 & 634,46 \\
\hline 26 & Rio Grande do Sul & $2.455,35$ & 2,57 & 634,46 \\
\hline 27 & Rio de Janeiro & $2.350,39$ & 2,46 & 607,34 \\
\hline
\end{tabular}

Fonte: Elaborado pelos autores a partir das tabelas salariais dos Estados, 2018.

A tabela 1 mostra que, se a remuneração de um trabalhador pode ser vista como um dos consistentes indicadores do grau de valorização que os profissionais recebem, é possível notar que os estados brasileiros não valorizam seus professores. $\mathrm{E}$, quando comparada com as outras carreiras, o quadro de remunerações evidencia ainda mais a pouca valorização docente.

\section{Uma vida de trabalho pouco valorizado}

A constituição do professor da educação básica no Brasil, ao longo da carreira, envolve questões ligadas ao ciclo de vida e ao desenvolvimento profissional, conforme teorizado por diversos autores, tais como Nóvoa (1995), Huberman (2000) e Marcelo (2009). Também, existem peculiaridades da vida profissional dos professores interligadas por questões de temporalidade, condições de trabalho e carreira. Nessa conjuntura, encontram-se possibilidades de um ciclo, com etapas semelhantes, ao longo dos anos que o professor permanece em atuação.

Embora Huberman (2000) ressalte que sua investigação (contextualizada na realidade europeia) não possa ser assertiva quanto à existência de um ciclo peremptório, definitivo e unívoco, seus estudos apontam para características comuns, conforme o tempo de atuação dos professores. Independentemente da conclusão, se existem ou não

11 Carga na carreira é de 30 horas. O valor apresentado, de 40 horas, foi calculado pelos autores do artigo. 
etapas na carreira docente, o que não se pode negar é que a intensificação, a desvalorização e a precarização do trabalho provocam efeitos negativos sobre quaisquer pessoas e em quaisquer momentos da vida profissional. Nessa perspectiva, o que temos no horizonte político-administrativo brasileiro é justamente o aumento de cobranças, de responsabilizações, da precarização das condições de trabalho e diminuição da remuneração para os professores.

A realidade em que a educação é obrigada a apresentar reduções de gastos, tornando-se, cada vez mais, alvos de controle, cobranças e resultados por meio de provas sistêmicas, coloca os professores em acentuado estado de intensificação do trabalho. Assunção e Oliveira (2009, p. 355) explicam que:

À medida que se tornam mais complexas as demandas às quais as escolas devem responder, também se complexificam as atividades dos docentes. Estes se encontram muitas vezes diante de situações para as quais não se sentem preparados, seja pela sua formação profissional ou mesmo por sua experiência pregressa. Quanto mais pobre e carente o contexto no qual a escola está inserida, mais demandas chegam até elas e, consequentemente, aos docentes.

Os autores remetem à intensificação do trabalho docente travestida de complexidades maiores para o aumento da eficiência. Duarte (2010) destaca que os professores têm se ocupado com tarefas e atribuições administrativas relacionadas ao ensino, à gestão dos currículos e da escola, motivados por questões relacionadas à produtividade e ao controle burocrático do trabalho docente. Segundo esse autor, existe ainda a autointensificação do trabalho docente, cuja busca se dá por níveis inatingíveis que os próprios professores (comprometidos com o seu trabalho) se impõem, a partir de pressões implementadas em reformas educacionais e processos externos de avaliação. Nesse cenário, diante da impossibilidade de corresponder a tantas expectativas, a intensificação se torna perversa, causa sofrimentos diversos e insatisfação, podendo levar ao adoecimento. Assim, Duarte (2010, p. 4) conclui que

[...] a intensificação do trabalho docente está registrada como tendência do trabalho docente na atualidade, em várias pesquisas, não importando o nível 
ou as etapas, ou seja, está presente no trabalho dos professores na educação superior (graduação e pós-graduação) e na educação básica (educação infantil, ensino fundamental e ensino médio.

As lutas dos trabalhadores da educação garantiram reconhecimentos legais da necessidade de comprometimento do poder público para com os professores brasileiros. Exemplo, o Plano Nacional de Educação (PNE), de 2014 a 2024, e o Plano Distrital de Educação (PDE), de 2015 a 2024. No PNE lemos: "Meta 17: valorizar os(as) profissionais do magistério das redes públicas de educação básica, de forma a equiparar seu rendimento médio ao dos(as) demais profissionais com escolaridade equivalente, até o final do sexto ano de vigência deste PNE" (BRASIL, 2014, p. 81). Em consonância, no Distrito Federal, a meta 17 trata da mesma temática, com a seguinte redação:

Meta 17: Valorizar os profissionais da educação da rede pública de educação básica ativos e aposentados, de forma a equiparar seu vencimento básico, no mínimo, à média da remuneração das demais carreiras de servidores públicos do Distrito Federal com nível de escolaridade equivalente, até o quarto ano de vigência deste Plano (DISTRITO FEDERAL, 2015, p. 43).

Em si, as metas estipulam um prazo para o Governo pôr em vigor a elevação da remuneração dos professores. Também, serve para reconhecer o quanto os trabalhadores do magistério possuem remunerações inferiores aos demais profissionais com similares graus de escolarização. No Brasil, a instituição de leis que garantam princípios de valorização para os professores nem sempre equacionam a questão. Um exemplo é a lei que criou o Piso Nacional do Magistério - Lei n 11.738 , de 2008 - que enfrenta inúmeros questionamentos jurídicos impetrados por diversos governos, no intuito de não pagarem a remuneração mínima estipulada pela Lei.

Tanto o piso quanto os planos de carreira do magistério são princípios registrados na Constituição Federal há mais de 20 anos, porém esforços para que sejam regulamentados e materializados têm sido bloqueados por resistências suprapartidárias, que conclamam a chancela do Supremo Tribunal Federal para a retificação de sua constitucionalidade [...] (MACHADO, 2012, p. 502). 
Desde a aprovação da referida Lei, por exemplo, governadores, prefeitos e diversos outros sujeitos da política partidária e suprapartidária têm tentado conseguir sua anulação. Não obstante os discursos recorrentes em prol da valorização necessária e inquestionável que se faz mister para a carreira docente, na prática, a ação da classe política segue em direção contrária.

Ainda assim, se a remuneração é importante indicador do grau de valorização e prestígio de uma profissão, então, mesmo no Distrito Federal, por exemplo, onde os professores estão entre os que recebem as melhores remunerações no Brasil, a carreira do Magistério Público é uma das menos valorizadas entre as que exigem formação de nível superior. Podemos analisar e constatar tal fato por meio dos dados apresentados na Tabela 2:

Tabela 2 - Remuneração básica das carreiras do Governo do Distrito Federal

\begin{tabular}{c|l|c|c}
\hline \multicolumn{2}{c|}{ Carreira } & Carga & Inicial (R\$) \\
\hline 1 & $\begin{array}{l}\text { Procurador / Defensor de Assistência } \\
\text { Judiciária }\end{array}$ & 30 & $22.589,59$ \\
\hline 2 & Defensor Público & 30 & $22.589,59$ \\
\hline 3 & Procurador do DF & 30 & $22.589,59$ \\
\hline 4 & Delegado de Polícia & 40 & $16.830,85$ \\
\hline 5 & Perito da Polícia Civil & 40 & $16.830,85$ \\
\hline 6 & Auditor Tributário & 40 & $14.970,00$ \\
\hline 7 & Auditor de Controle Interno & 40 & $12.800,00$ \\
\hline 8 & Médicos & 40 & $12.654,00$ \\
\hline 9 & Regulador de Serviços Públicos & 40 & $9.200,00$ \\
\hline 10 & Auditor Fiscal de Atividades Urbanas & 40 & $9.001,88$ \\
\hline 11 & Papiloscopista, Escrivão, Agente / Polícia Civil & 40 & $8.698,78$ \\
\hline 12 & Cirurgião - Dentista & 40 & $8.500,00$ \\
\hline 13 & Analista de Planejamento e Gestão Urbana e & 40 & $8.466,67$ \\
& Regional & & \\
\hline 14 & Músico & 40 & $8.431,03$ \\
\hline 15 & Analista de Trânsito & 40 & $8.296,47$ \\
\hline 16 & Especialista do Sistema Socioeducativo & 40 & $7.679,36$ \\
\hline 17 & Apoio às Atividades Jurídicas & 40 & $7.320,00$ \\
\hline
\end{tabular}




\begin{tabular}{|c|c|c|c|}
\hline \multicolumn{2}{|r|}{ Carreira } & \multirow{2}{*}{$\frac{\text { Carga }}{40}$} & \multirow{2}{*}{\begin{tabular}{|c|} 
Inicial (R\$) \\
$7.290,00$
\end{tabular}} \\
\hline 18 & $\begin{array}{l}\text { Especialista em Atividades de Transportes } \\
\text { Urbanos }\end{array}$ & & \\
\hline 19 & Analista de Gestão Fazendária & 40 & $7.020,00$ \\
\hline 20 & Analista de Gestão e Fiscalização Rodoviária & 40 & $6.872,95$ \\
\hline 21 & Agente de Trânsito & 40 & $6.792,50$ \\
\hline 22 & Analista de Atividades Culturais & 40 & $6.760,00$ \\
\hline 23 & Analista de Atividades do Hemocentro & 40 & $6.760,00$ \\
\hline 24 & Analista de Atividades do Meio Ambiente & 40 & $6.760,00$ \\
\hline 25 & $\begin{array}{l}\text { Analista em Fiscalização e Desenvolvimento } \\
\text { Agropecuário }\end{array}$ & 40 & $6.760,00$ \\
\hline 26 & Gestor de Apoio às Atividades Policiais Civis & 40 & $6.760,00$ \\
\hline 27 & Analista de Gestão de Resíduos Sólidos & 40 & $6.760,00$ \\
\hline 28 & $\begin{array}{l}\text { Gestor de Políticas Públicas e Gestão } \\
\text { Governamental }\end{array}$ & 40 & $6.760,00$ \\
\hline 29 & Especialista de Assistência Social & 40 & $6.239,48$ \\
\hline 30 & Especialista em Saúde & 40 & $6.110,00$ \\
\hline 31 & Enfermeiro & 40 & $6.110,00$ \\
\hline 32 & Soldado de 2a Classe Bombeiro Militar & Escala & $6.052,88$ \\
\hline 33 & Soldado de $2^{\text {a }}$ Classe Polícia Militar & Escala & $6.052,88$ \\
\hline 34 & Assistente de Trânsito & 40 & $6.006,00$ \\
\hline 35 & Agente do Sistema Socioeducativo & 40 & $5.720,01$ \\
\hline 36 & Técnico do Sistema Socioeducativo & 40 & $5.546,67$ \\
\hline 37 & Apoio à Assistência Judiciária12 & 35 & $4.641,22$ \\
\hline 38 & Analista do Procon & 40 & $5.293,30$ \\
\hline 39 & $\begin{array}{l}\text { Professores da Educação Básica - Magistério } \\
\text { Público }\end{array}$ & 40 & $5.016,52$ \\
\hline 40 & $\begin{array}{l}\text { Analista de Políticas Públicas e Gestão } \\
\text { Governamental }\end{array}$ & 40 & $4.480,00$ \\
\hline 41 & Analista de Gestão Educacional & 40 & $4.076,99$ \\
\hline
\end{tabular}

Fonte: SEPLAG, 2018, adaptado pelos autores.

12 Devido à carga horária dessa carreira ser de 35 horas, calculando o proporcional a 40 horas, ela se posiciona acima das demais. O proporcional de 40 horas nesse caso seria de 5.304,25. 
Na capital do país, os professores precisariam de um aumento em sua remuneração inicial de, aproximadamente $80 \%$ para que a meta fosse alcançada. Outra vez, as opiniões de setores de grande influência acerca dos caminhos do país nos próximos anos, a respeito do papel dos professores, vão em direções distintas. O Banco Mundial (2017, p. 129) ressalta que:

\begin{abstract}
A ineficiência dos ensinos fundamental e médio está principalmente relacionada ao número excessivo de professores. [...] Alternativamente, a redução do número de professores com base no número atual de alunos representaria uma economia de aproximadamente 22 bilhões (ou 0,33\% do PIB), dos quais 17 bilhões no ensino fundamental, e 5 bilhões no ensino médio. [...].
\end{abstract}

Sem nunca discutir as condições salariais da carreira docente, o Banco Mundial - tão ouvido por governantes brasileiros - prefere calcular as cifras que necessitam de economia e de aumento da carga de trabalho sobre os professores. Isso porque, com a diminuição do número de professores, o primeiro efeito a se perceber é o aumento da jornada de trabalho e do número de alunos, por sala de aula, para os docentes em atuação.

Há uma linha de raciocínio que diz que a educação pública brasileira, com grande parte de seus professores concursados e estáveis, precisaria diminuir significativamente o número de seus docentes para atender à orientação do Banco Mundial, cuja solução é atroz:

Em grande parte, esse problema poderia ser solucionado por meio da não reposição de parte dos professores que estarão se aposentando em breve. A redução do número de professores por meio da aposentadoria poderia ajustar as razões a níveis eficientes no ensino fundamental até 2027 e, no ensino médio, até 2026. [...] (Ibidem, p. 129).

Em sua análise, além de não discutir a realidade do Brasil como país subdesenvolvido, culpabiliza os professores de diversas formas, incluindo acusações de serem privilegiados pelo Estado e de prejudicarem toda a nação: "Vale destacar que, devido às generosas regras previdenciárias dos professores, os aposentados do setor ainda impõem custos orçamentários aos estados e municípios por meio do sistema previden- 
ciário [...]" (Ibidem, p. 129). Claramente, os especialistas do Banco pautam suas análises pela ótica da economia de gastos, dos contingenciamentos e cortes orçamentários, sobretudo aqueles que não representam geração de lucros diretos ou de mais-valia.

A educação pública é uma das áreas que o capital enxerga, tanto como possibilidade de geração de lucros acentuados para a iniciativa privada (uma vez que a rede pública deixasse de ser tão extensa), quanto como uma fonte de gastos da verba pública. Na perspectiva neoliberal, esse setor poderia realocar divisas para investimentos em infraestrutura, os quais, em última instância, se voltariam para os negócios privados, permitindo ao país maiores reservas para o pagamento das dívidas com seus credores, inclusive o Banco Mundial.

As forças neoliberais lutam para a obtenção de tal controle, mas enfrentam a realidade do trabalho imaterial que requer um movimento ideológico que garanta a alienação. Produto e produtor, nesse caso, não se dissociam, constituindo-se, assim, em um dificultador para a plenitude do controle do capital, sobretudo pela impossibilidade de garantir uma mais-valia direta. Aliás, uma das características do trabalho docente diz respeito ao fato de se tratar de um serviço; um trabalho imaterial e improdutivo, cuja "[...] produção é inseparável do ato de produzir, como sucede com todos os artistas executantes, oradores, atores, professores, médicos, padres etc" (MARX, 1980, p. 403). Por isso, a educação precisa ser precarizada, aproximada ao máximo da lógica que rege o trabalho material, para fazer com que os professores possam, de formas diversas, gerar lucros ou economias aos cofres públicos pelo exercício de seu trabalho.

Finalmente, dentro do programa de governo do novo Presidente, podemos encontrar as propostas para fazer da educação brasileira um setor desenvolvido e eficaz. Segundo o seu programa de governo:

\footnotetext{
Além de mudar o método de gestão, na educação também precisamos revisar e modernizar o conteúdo. Isso inclui a alfabetização, expurgando a ideologia de Paulo Freire, mudando a Base Nacional Comum Curricular (BNCC), impedindo a aprovação automática e a própria questão de disciplina dentro das escolas. [...] Um dos maiores males atuais é a forte doutrinação (BRASIL, 2018, p. 46).
}

Uma vez mais, os professores brasileiros não são mencionados em planos de melhorias da educação nacional, senão como um dos cau- 
sadores de seus problemas. Essa prática já vem sendo feita no Brasil ao longo de toda a história da educação brasileira, em maior ou menor grau. Então, aqui é interessante lembrarmos as palavras de Marx, quando ele afirma que:"[...] todos os grandes fatos e todos os grandes personagens da história mundial são encenados, por assim dizer, duas vezes. [...] a primeira vez como tragédia, a segunda como farsa [...]" (MARX, 2011, p. 25). Assim, as "muitas vezes" em que retornam as ideias de supressão de direitos dos trabalhadores docentes e ataques contra a educação pública - que ainda resiste e oferece oportunidades de emancipação aos filhos das classes subalternas - superam as "duas vezes" que Marx cita acerca da encenação dos fatos históricos no Brasil.

\section{Considerações finais}

O trabalho docente é uma atividade sem a qual não se pode desenvolver a educação escolar das crianças, dos jovens e adultos, sobretudo na educação básica, para a qual a rede pública é a que alcança os lugares mais longínquos, as pessoas excluídas socioeconomicamente e com as particularidades mais complexas; mais que ensino, a rede pública também oportuniza a socialização, a alimentação, a inclusão e a esperança a milhões de estudantes e suas famílias. Para uma empresa, na estrita filosofia liberal, esse caráter social não se constitui sua obrigação e, por consequência, não tem como meta aplicá-lo.

Conforme o Banco Mundial, se os professores brasileiros são privilegiados com salários maiores que os pagos em outros países e, se nessa condição, gozam de aposentadorias generosas, que oneram sobremaneira os cofres públicos; se, para o novo comando do Brasil escolhido pela população através do voto -, os professores doutrinam crianças e jovens para ideologias comunistas e profanas contra a moral, os princípios religiosos e familiares tradicionais, então, os dados atestam uma realidade muito diferente.

A remuneração do magistério público no Brasil encontra-se, na maior parte dos casos, muito abaixo de outros cargos com a mesma formação e carga horária, incluindo outros cargos de escolaridade menor. Quanto à doutrinação, carece de dados ou de indícios que apontem a veracidade dessa argumentação. Ao que parece, trata-se de uma acusação derivada, talvez, da quantidade de greves e movimentos deflagrados pelos professores (com notável constância no país) em busca de mínimas melhorias, 
podendo ser interpretado por algumas pessoas como uma atitude própria de "esquerdistas". Essa interpretação, por ignorância ou dolo, não leva em conta o quadro de abandono observado através de dados empíricos, por meio dos quais se observa menosprezo, desvalorização e precariedade da docência, além dos sedentos interesses de setores privados pelo controle da oferta da educação como mercadoria e não mais como direito.

Há muito tempo, o trabalho docente sofre com a precarização, com a intensificação e com a desvalorização. Os dados apresentados nas Tabelas 1 e 2 mostram o quanto se trata de um trabalho menosprezado pelo Estado. Até mesmo na Capital Federal, onde o funcionalismo público figura como imprescindível, central e mais bem pago, a carreira docente aponta uma das mais baixas remunerações.

Contudo, os docentes brasileiros, em todos os níveis da educação, ainda não perderam sua coragem de lutar e arrancar conquistas. Mesmo nesse cenário desafiador, no qual se começa a criar a imagem dos professores como inimigos da nação, oxalá possam prosseguir confiantes na vitória, pelo bem do Brasil. E que nada os detenha...

\section{Referências}

ACRE. Lei Complementar no 330/2017. Altera dispositivos da Lei Complementar n 67, de 29 de junho de 1999, que dispõe sobre o Plano de Cargos, Carreira e Remuneração PCCR dos Profissionais do Ensino Público Estadual, e Lei no 1.704 de 26 de janeiro de 2006. Diário Oficial do Estado do Acre, Rio Branco, 2017. Disponível em: http://www.al.ac. leg.br/leis/wp-content/uploads/2017/03/LeiComp330.pdf. Acesso em: 28 dez. 2018.

AMAPÁ. Lei no 2322/2018. Incorpora a Gratificação de Regência de Classe (GRC), Gratificação para Pedagogos, Auxiliares Educacionais e Especialistas (GPAE) e a Gratificação de Suporte Técnico e Pedagógico (GSTP) ao vencimento base dos profissionais da Educação Básica do Poder Executivo Estadual. Diário Oficial do Estado do Amapá, Macapá, 9 abr. 2018. Disponível em: http://www.al.ap.gov.br/ver_texto_lei. php?iddocumento=88476. Acesso em: $28 \mathrm{dez} .2018$.

AMAZONAS. Lei $n^{\circ} 4.578 / 2018$. Altera, na forma que especifica, a remuneração de todos os servidores da Secretaria de Estado de Educação e Qualidade do Ensino, e dá outras providências. Diário Oficial do Estado do Amazonas. Manaus, 8 abr. 2018. 
Disponível em: https://sapl.al.am.leg.br/media/sapl/public/norma juridica/2018/10058/10058_texto_integral.pdf. Acesso em: 28 dez. 2018. APEOC. Sindicato dos Servidores Públicos lotados nas Secretarias de Educação e de Cultura do Estado do Ceará e nas Secretarias ou Departamentos de Educação e/ou Cultura dos Municípios do Ceará. Tabelas de Remuneração 2018. Disponível em: https://apeoc.org. br/sindicato-apeoc-divulga-tabela-salarial-do-magisterio-de-2018/. Acesso em: 28 dez. 2018.

SINDICATO DOS PROFESSORES DO ENSINO OFICIAL DO ESTADO DE SÃO PAULO. Salário Base 2018. Disponível em: http://www.apeoesp.org.br/ salario-base/. Acesso em: 28 dez. 2018.

SINDICATO DOS TRABALHADORES EM EDUCAÇÃO PÚBLICA DO PARANÁ. Tabelas Salariais 2018. Disponível em: http://appsindicato.org.br/ tabela-de-vencimentos/. Acesso em: 28 dez. 2018.

SINDICATO DOS TRABALHADORES EM EDUCAÇÃO DO ESTADO DO PARANÁ. Tabela de vencimentos. Disponível em: http://appsindicato. org.br/professores/. Acesso em: 28 dez. 2018.

ASSUNÇÃO A. A.; OLIVEIRA D. O. Intensificação do trabalho e saúde dos Professores. Educ. Soc., Campinas, v. 30, n. 107, p. 349-372, maio/ ago. 2009. Disponível em: http://www.scielo.br/pdf/es/v30n107/03.pdf. Acesso em: 30 dez. 2018.

BANCO MUNDIAL. Ajuste Justo: Análise da eficiência e equidade do gasto público no Brasil. 2017. Disponível em: http://documents. worldbank.org/curated/en/884871511196609355/pdf/121480REVISED-PORTUGUESE-Brazil-Public-Expenditure-Review-OverviewPortuguese-Final-revised.pdf. Acesso em: 10 nov. 2017.

BRASIL. PNE: Plano Nacional de Educação 2014-2024. Lei n 13.005, de 25 de junho de 2014, que aprova o Plano Nacional de Educação (PNE) e dá outras providências. Brasília: Câmara dos Deputados, Edições Câmara, 2014. 86 p. Disponível em http://www2.camara.leg. br/legin/fed/lei/2014/lei-13005-25-junho-2014-778970-norma-pl.html. Acesso em: 10 jan. 2018.

BRASIL. Tribunal Superior Eleitoral. Programa de Governo do Partido Social Liberal. Brasil acima de tudo. Deus acima de todos. 2018. Disponível em: http://divulgacandcontas.tse.jus.br/ 
candidaturas/oficial/2018/BR/BR/2022802018/280000614517// proposta_1534284632231.pdf. Acesso em: 31 dez. 2018.

BRESSER-PEREIRA, L. C.; SPINK, P. (Org.). Reforma do Estado e Administração Pública Gerencial. Rio de Janeiro: Editora Fundação Getúlio Vargas, 1998.

CASTELLS, M. A sociedade em rede. São Paulo: Paz e Terra, 1999.

CURY, Carlos Roberto Jamil. Educação e Contradição: Elementos metodológicos para uma teoria crítica do fenômeno educativo. São Paulo: Cortez - Autores Associados, 1989.

DIEESE. Departamento Intersindical de Estatísticas e Estudos Socioeconômicos. Nota técnica no 188 de 2018. Valor de $\mathbf{9 5 4 , 0 0}$ não recompõe poder de compra do Salário Mínimo. 2018. Disponível em: https://www.dieese.org.br/notatecnica/2018/notaTec 188SalarioMinimo.html. Acesso 31 dez. 2018.

DISTRITO FEDERAL. PDE: Plano Distrital de Educação 2015-2024. Lei no 5.499, de 14 de julho de 2015. Aprova o Plano Distrital de EducaçãoPDE e dá outras providências. Brasília: Governo do Distrito Federal, 2015. Disponível em: http://www.cre.se.df.gov.br/ascom/documentos/ pde_15_24.pdf. Acesso em: 19 dez. 2018.

DISTRITO FEDERAL. Secretaria de Estado de Planejamento, Orçamento e Gestão (SEPLAG). Carreiras do DF. Brasília, 2018. Disponível em: http:// www.seplag.df.gov.br/carreiras-do-df/. Acesso em: 10 jul. 2018.

DUARTE, A.M.C. Intensificação do trabalho docente. In: OLIVEIRA, D.A.; DUARTE, A.M.C.; VIEIRA, L.M.F. DICIONÁRIO: trabalho, profissão e condição docente. Belo Horizonte: UFMG/Faculdade de Educação, 2010. Disponível em: http://www.gestrado.net.br/index.php?pg=dicionarioverbetes\&id=66. Acesso em: 20 jan. 2018

FACCl, M.G. D. Valorização ou esvaziamento do trabalho do professor? Um estudo crítico-comparativo da teoria do professor reflexivo, do construtivismo e da psicologia vigotskiana. Campinas, SP: Autores Associados, 2004.

FETEMS. Federação dos Trabalhadores em Educação do Mato Grosso do Sul. Tabela de Salários. 2018 Disponível em: https://www.fetems.org.br/ Informacoes/mocoes/menu:3/submenu:11/. Acesso em: 28 dez. 2018. 
GOVERNO DO ESTADO DO RIO GRANDE DO SUL. Estado confirma pagamento de reajuste ao completivo do magistério para 2018. Disponível em: https://estado.rs.gov.br/estado-confirma-pagamento-dereajuste-ao-completivo-do-magisterio-para-2018. Acesso em: 28 dez. 2018. GRAMSCl, Antônio, Cadernos do cárcere. Vol. 2, 4 ed. Rio de Janeiro: Civilização Brasileira, 2006.

HARVEY, D. O Neoliberalismo: História e implicações. São Paulo: Edições Loyola, 2008.

HUBERMAN, M.; O ciclo de vida profissional de professores. In: Nóvoa, A. (org.) Vida de professores. Porto Editora. 2000.

HYPOLITO, Álvaro Moreira; GRISHCKE, Paulo Eduardo. Trabalho imaterial e trabalho docente. Educação, Santa Maria, v.38, n.3, p. 507-522, set./ dez. 2013. ISSN 1984-6444. Disponível em: https://periodicos.ufsm.br/ reveducacao/article/view/8998. Acesso em: 17 jul. 2018.

INFOMONEY. Real vs Moedas. 2018. Disponível em: https://www. infomoney.com.br/mercados/cambio. Acesso em: 31 dez. 2018.

LUKÁCS, G. Os princípios ontológicos fundamentais de Marx. São Paulo: Ciências Humanas, 1979.

MACHADO, J. de P. Piso e planos de carreira $\mathbf{O}$ debate sobre as ADI. Revista Retratos da Escola, Brasília, v. 6, n. 11, p. 489-505, jul./dez. 2012. Disponível em: http://retratosdaescola.emnuvens.com.br/rde/article/ view/223/411. Acesso em: 10 jan. 2019.

MARCELO, C. Desenvolvimento profissional docente: passado e futuro. Sísifo - Revista de Ciências da Educação, Lisboa, n. 8, p. 7-22, jan./abr. 2009.

MARX, K. O Capital: Teorias da mais-valia., 5. ed. Rio de Janeiro: Civilização Brasileira, 1980. v.l, cap, 4.

MARX, K. O 18 Brumário de Luís Bonaparte. [Tradução de Nélio Schneider]. São Paulo: Boitempo, 2011.

NÓVOA, A. O passado e o presente dos professores. In: NÓVOA, António. Profissão Professor. Porto: Porto Editora, 1995.

PIAUÍ - GOVERNO DO ESTADO. Piauí avança na valorização salarial de professores. 07 de março de 2018. Disponível em: http://www. 
pi.gov.br/materia/educacao/piaui-avanca-na-valorizacao-salarial-deprofessores-4908.html. Acesso em: 28 dez. 2018.

RORAIMA. Lei $n^{\circ} 1.030 / 2016$. Altera e acrescenta dispositivos na Lei $n^{\circ}$ 892, de 25 de janeiro de 2013, que dispõe sobre o Plano de Cargos, Carreiras e Remunerações dos Servidores da Educação Básica do Estado de Roraima (PCCREB), e dá outras providências. Disponível em: http://www.transparencia.rr.gov.br/phocadownload/tabela_remuneracao/PCCR_LEI1030_16.pdf. Acesso em: 28 dez. 2018.

ROSANVALLON, P. A crise do Estado-Providência. [Tradução de Joel Pimentel de Ulhôa]. Goiânia: Editora da UnB, 1997.

SANTOS, M. Por uma outra globalização: do pensamento único à consciência universal. Rio de Janeiro: Record, 2017.

SINDIUPES. Sindicato dos(as) Trabalhadores(as) em Educação Pública do Espírito Santo. Tabelas de Vencimentos. Disponível em: http:// sindiupes.org.br/wp-content/uploads/2013/09/tabelas-vencimentos-1. jpg. Acesso em: 28 dez. 2018.

SINPRO - DF. Sindicato dos Professores do Distrito Federal. Tabelas Salariais. Disponível em: http://www.sinprodf.org.br/tabelas/. Acesso em: 28 dez. 2018.

SINPROESEMMA. Sindicato dos Trabalhadores em Educação Básica das Redes Públicas Estadual e Municipais do Maranhão. Tabela Salarial 2018. Disponível em: http://www.sinproesemma.org.br/tabela-salarialestatuto-do-educador-e-outras-leis-2/. Acesso em: 28 dez. 2018.

SINTE - Sindicato dos Trabalhadores em Educação de Santa Catarina. Valores Salariais 2018. Disponível em: http://www.sinte-sc.org. br/files/1081/VALORES\%20SALARIAIS\%20A\%20PARTIR\%20DE\%20 MAIO\%202018.pdf. Acesso em: 28 dez. 2018.

SINTEAL. Sindicato dos Trabalhadores da Educação de Alagoas. Tabela do magistério 2018. Disponível em: http://www.sinteal.org.br/tipo-dearquivo/documentos/. Acesso em: 28 dez. 2018.

SINTEGO. Sindicato dos Trabalhadores em Educação do Estado de Goiás. Tabelas Salariais 2018. Disponível em: http://sintego.org.br/midias/ downloads/10072018130556.pdf. Acesso em: 28 dez. 2018. 
SINTEP - MT. Sindicato dos Trabalhadores no Ensino Público de Mato Grosso. Tabelas Salariais 2018. Disponível em: http://sintep2.org.br/ Arquivos/tabela/Tabelas-Outubro-2018.pdf. Acesso em: 28 dez. 2018.

SINTEPE. Sindicato dos Trabalhadores em Educação do Estado de Pernambuco. Tabela salarial 2018. Disponível em: https://www. sintepe.org.br/site/v1/index.php/component/content/article/89destaque/4732-tabela-salarial-2018. Acesso em: 28 dez. 2018.

SINTEPPB. Sindicato dos Trabalhadores e Trabalhadoras em Educação do Estado da Paraíba. Tabela de Vencimento 2017. Disponível em: http://www.sinteppb.com.br/arquivos/tabela-de-vencimentos-2017. pdf. Acesso em: 28 dez. 2018.

SINTERN. Sindicato dos Trabalhadores em Educação do Estado do Rio Grande do Norte. Tabela Salarial. Disponível em: http://sintern.org.br/ blog/confira-a-tabela-salarial-com-os-percentuais-do-reajuste-do-pisosalarial-nacional-para-os-trabalhadores-em-educacao-do-estado-e-denatal/. Acesso em: 28 dez. 2018.

SINTERO. Sindicato dos Trabalhadores de Educação do Estado de Rondônia. Sintero esclarece alteração da nova tabela salarial dos professores estaduais após a greve. 17 de abril de 2018. Disponível em: http://www.sintero.org.br/noticias/geral/sintero-esclarece-alteracaoda-nova-tabela-salarial-dos-professores-estaduais-apos-a-greve/1322. Acesso em: 28 dez. 2018.

SINTESE. Sindicato dos Trabalhadores em Educação do Estado de Sergipe. Tabela Rede Estadual 2017. Disponível em: http://www. sintese.org.br/educacao/rede-estadual/tabela-salarial.html. Acesso em: 28 dez. 2018.

SINTET. Sindicato dos Trabalhadores em Educação do Estado do Tocantins. Tabelas de vencimentos da rede estadual. Disponível em: http://sintet.org.br/documentos.php. Acesso em 28 dez. 2018.

TRADING ECONOMICS. Trabalho dos Estados Unidos. 2018. Disponível em: https://pt.tradingeconomics.com/united-states/average-hourlyearnings. Acesso em: 31 dez. 2018.

UPPES. União dos Professores Públicos no Estado do Rio de Janeiro. Defasagem Salarial: Triste realidade do magistério público 
estadual. 2018. Disponível em: http://site.uppes.com.br/defasagemsalarial-triste-realidade-do-magisterio-publico estadual/. Acesso em: 28 dez. 2018.w

Recebido: abril/ 2019

Aceito: julho/2019 